\title{
MIMESIS POÉTICA Y CRÍTICA AL TEATRO EN LA CARTA A D'ALEMBERT
}

\section{Gabriela Domecq*}

\section{Resumen}

Este trabajo se propone analizar la crítica al teatro que encontramos en la Carta a d'Alembert para determinar qué concepción de la mimesis poética la sustenta. Quisiéramos mostrar que la crítica a la concepción clásica de la catarsis que encontramos en la Carta no supone por parte de Rousseau la adopción de la concepción platónica de la mimesis poética. Empezaremos por ubicar la referencia al teatro en la obra. En un segundo momento situaremos su crítica en el contexto de la disputa en torno a la moralidad del teatro que se dio en Francia a lo largo de los siglos XVII y XVIII. Esta disputa nos interesa porque los argumentos a favor o en contra de la moralidad del teatro se basan en el análisis de los efectos de la mimesis poética sobre las pasiones. Luego de analizar la posición de Rousseau sobre los límites de la catarsis poética nos preguntaremos en un tercer y último momento si su cuestionamiento a la moralidad del teatro supone la concepción platónica de la mimesis poética. Veremos que Rousseau, próximo a Platón en el análisis de las consecuencias morales del teatro, se aleja de él en tanto no concibe la mimesis como copia de la naturaleza.

Palabras clave: Rousseau, mimesis poética, catarsis, moral, teatro.

\begin{abstract}
This paper intends to analyze the critique of theatre found in the Letter to D'Alembert, to determine the conception of poetic mimesis that underlies it. We should like to show, that from the critique to the classical conception of catharsis found in the Letter, it does not follow that Rousseau adopted the platonic conception of poetic mimesis. We shall begin by identifying the reference to theatre within the work. In a second moment, we shall situate its critique in the context of the dispute about morality in theatre which took place in France throughout the $17^{\text {th }}$ and $18^{\text {th }}$ centuries. This dispute interests us, because arguments for or against

\footnotetext{
* Licenciada de filosofía por la Universidad Lyon III (Francia). Master en Filosofía por la Universidad Marc Bloch (Francia). Docente investigadora de la Universidad Nacional de General Sarmiento. Trabaja sobre la obra de Rousseau, en los temas de estética y política. Dirección electrónica : gdomecq@ungs.edu.ar
} 
morality in theatre are based on the analysis of the effects of poetic mimesis upon passions. After analysing Rousseau's position about the limits of poetic catharsis, we shall inquire, in a third and last moment, whether his questioning of morality of theatre supposes the platonic conception of poetic mimesis. We shall see that Rousseau, who nears Plato in the analysis of the moral consequences of theatre, moves away from him, inasmuch as he does not conceive mimesis as a copy of nature.

Keywords: Rousseau, poetic mimesis, catharsis, moral, theatre.

Mucho antes que el cristianismo, fue la filosofía la que dirigió sus armas contra el teatro. Esta contienda quedó plasmada en el libro III y X de la República de Platón, con la exclusión de los poetas de la ciudad bien ordenada. Las acusaciones del filósofo, que luego serán asumidas por el cristianismo, pueden resumirse en el poder de ilusión de la mimesis poética. La mimesis reproduce apariencia y confirma un aparente saber cuyo único resultado es el de enardecer las pasiones. El espectador se deleita ante apariencias que confunde con la verdad. Es a este desconocimiento y su consecuente poder de ilusión que la tradición atribuye los efectos nefastos del teatro.

La lectura platónica predomina en los estudios que se han ocupado de Rousseau y su crítica al teatro ${ }^{1}$. Según esta interpretación, Rousseau, al rechazar la instalación de un teatro en Ginebra, repetiría el gesto platónico de exclusión de los poetas. Tras la condena al teatro se encontraría entonces la caracterización de la imitación poética como forma no verdadera de reproducción de la naturaleza. El teatro sería otro de los "artificios" con los cuales la civilización nos aleja de la naturaleza, socavando la distancia entre el ser y el parecer.

En este trabajo examinaremos si la crítica al teatro que encontramos en la Carta a D'Alembert supone por parte de Rousseau la condena platónica a la mimesis poética. Empezaremos por ubicar la referencia al teatro en la obra. En un segundo momento, situaremos su crítica en el contexto de la

${ }^{1}$ Es la interpretación de Starobinski, Jean-Jacques Rousseau : la transparence et l'obstacle, Paris, Tel Gallimard, 1971; de Lacoue-Labarthe, Poétique de l'bistoire, Paris, Galilée, 2002 ; y, más recientemente de Charbonnel, Pbilosopbie de Rousseau, Lons-Le-Saunier, Aréopage, 2006. 
disputa en torno a la moralidad del teatro que se dio en Francia a lo largo de los siglos XVII y XVIII. Esta disputa nos interesa especialmente pues los argumentos a favor o en contra de la moralidad del teatro se basan en el análisis de los efectos de la mimesis poética sobre las pasiones. Luego de analizar la posición de Rousseau sobre los límites de la catarsis poética, nos preguntaremos en un tercer y último momento si su cuestionamiento a la moralidad del teatro supone la concepción platónica de la mimesis poética.

\section{La crítica al teatro en la obra de Rousseau}

\section{A. Breve recorrido}

Rousseau hace su entrada en el mundo de las letras cuestionando el lugar de las ciencias y las artes en el progreso moral de los hombres. En el Discurso sobre las ciencias y las artes (1750) distingue moralidad y civilidad, buen gusto y buenas costumbres. Tanto las ciencias como las artes han contribuido a que la vida sea más confortable y las costumbres más refinadas, dice, pero este refinamiento no nos permite constatar una consecuente moralización en los hombres. Rousseau duda, pues, que las artes y las ciencias puedan conducir el progreso moral. La condena al teatro que aparece en la Carta a D'Alembert (1758), también conocida como Carta sobre los espectáculos ${ }^{2}$, se inscribe en el marco de esta crítica.

Ahora bien, aunque las bellas artes en general y en particular el teatro no puedan ser los motores del progreso moral, en un texto de 1752 , el prefacio a Narciso, Rousseau reconoce sin embargo que el teatro cumple una función social positiva en las sociedades decadentes. Allí donde las costumbres han envilecido el corazón de los hombres, el teatro los distrae de cometer daños mayores ${ }^{3}$. Esta idea será retomada en la Carta. En la Nueva Eloisa, por su parte, contemporánea de la Carta pero publicada por primera vez en 1760 , las cartas XVII y XXIII están dedicadas a la descripción y a la crítica de la ópera y del teatro parisino: un teatro ampuloso y facticio, afirma, que representa héroes fabulosos y mundos dorados dejando al hombre común fuera del escenario. En las Consideraciones sobre el gobierno de Polonia

2 Rousseau, J.-J., Lettre à D'Alembert, Paris, Gallimard, 1995. Citaremos esta edición como "Lettre".

${ }^{3}$ Rousseau, J.-J., Narcisse, Paris, Gallimard, 1964, p. 972. 
(1771), finalmente, encontramos la oposición planteada en la Carta entre el teatro y la fiesta. Rousseau aconseja excluir de la vida pública el teatro, la comedia y la ópera, e inventar en su lugar "fiestas y juegos" al aire libre 4 .

De todas maneras, es sin duda en Emilio (1762) donde la cuestión del teatro y el problema de la mimesis poética aparecen con mayor intensidad. La imitación está presente como una dimensión propia de la naturaleza humana, tópico que encontramos también en el Segundo discurso, donde el hombre es definido como un animal mimético. En Emilio esta idea se prolonga en un sentido aristotélico. El hombre aprende imitando, y goza de las imitaciones. La imitación para Rousseau forma parte de la naturaleza humana; es por la imitación que el niño es conducido a la moralidad. "El hombre es imitador, sostiene Rousseau, el animal también lo es; el gusto por la imitación forma parte de la naturaleza bien ordenada, pero degenera en sociedad" 5 . En nuestro trabajo intentaremos determinar en qué medida el teatro contribuye, o no, a esta degeneración de la imitación en la sociedad. El teatro es de todas formas incluido en la educación de Emilio. El preceptor lleva a Emilio adolescente al teatro, no para instruirlo y moralizarlo, sino para estudiar el gusto. "No hay escuela, afirma Rousseau, donde se aprenda mejor el arte de agradar a los hombres y cautivar el corazón humano"6.

Este breve recorrido por la obra de Rousseau nos permite constatar que la preocupación por el teatro no se limita a un escrito de circunstancia. Por otra parte, las críticas que aquí hemos señalado dejan entrever que existen para el autor aspectos valiosos en la imitación poética.

\section{B. La Carta a D'Alembert}

Rousseau escribe la Carta” en respuesta al artículo "Ginebra" que D’Alembert publica en la Encyclopedie en 1757 y en el cual dedica un párrafo

\footnotetext{
4 Rousseau, J.-J., Considération sur le Gouvernement de Pologne, Paris, Gallimard, 1964, pp. 962-964.

5 Rousseau, J.-J., Emile, Paris, Gallimard, 1954, p. 340.

${ }^{6}$ Rousseau, J.-J., Emile, p. 677.

${ }^{7}$ En el libro X de las Confesiones Rousseau describe las circunstancias que lo llevaron a escribir esta obra.
} 
a promover la instalación de un teatro en Ginebra. Con su artículo, D’Alembert, y detrás de él Voltaire ${ }^{8}$, intervienen en la disputa que opone en Ginebra el partido popular compuesto por "les citoyens $d u$ bas", al patriciado, "les citoyens $d u$ haut", que ejercen el poder en Ginebra. Los patricios, que desde el siglo XVII detentan el monopolio del gobierno, son los partidarios de la creación de un teatro estable en la ciudad. Los que se oponen son los representantes de la Iglesia protestante y los ciudadanos que han sido alejados del poder: viejas familias, artesanos de relojería y demás oficios. Rousseau toma posición en contra de los patricios denunciando los costos sociales y políticos que implica la instalación de un teatro en una ciudad pobre. Mantener un teatro es un costo que paga toda la comunidad, dice, pero que sólo algunos disfrutan. El teatro no sólo amenaza la moralidad por su influencia sobre las buenas costumbres, riesgo que D'Alembert propone sortear con leyes estrictas que regulen la conducta de los comediantes, sino, y de manera mucho más peligrosa, amenaza la igualdad por la transformación en la estructura socio económica que introduce? ${ }^{9}$. No nos detendremos en nuestro trabajo sobre este aspecto de la crítica, nos limitaremos a señalar sus conclusiones:

De estas nuevas reflexiones se sigue evidentemente, me parece, que los espectáculos modernos, donde sólo se asiste al precio del dinero, tienden sobre todo a favorecer y aumentar las desigualdades de las fortunas (...) Nunca en una Monarquía, la opulencia de un particular puede ponerlo por encima del Príncipe; pero en una República, puede muy fácilmente ponerlo por encima de las leyes. Entonces el gobierno no tiene fuerza, y el rico es siempre el verdadero soberano ${ }^{10}$.

8 Desde su instalación en las "Délices" (frontera con Ginebra) en 1755, Voltaire utiliza toda su influencia para lograr la creación de un teatro en Ginebra. Cfr. Solveig Schult Ulriksen, "Diderot et Rousseau. Le théâtre et la fête" in Rousseau Studies. http://rousseaustudies.free.fr/articleulriksen.html

9 El análisis de los "costos" que implica para la comunidad mantener un teatro ocupa el último tercio de la Lettre. En la edición citada corresponde a las páginas 8590 y 103-106.

${ }^{10}$ Lettre, p. 105. 
El argumento de D'Alembert para incitar a los ginebrinos a instalar un teatro en la ciudad es que el teatro permitiría conciliar los principios republicanos con el refinamiento de las costumbres. D'Alembert argumenta a favor del teatro sin aludir a su capacidad de instruir y moralizar al público, "las representaciones teatrales formarían el gusto de los ciudadanos, y les darían una fineza de tacto, una delicadeza en los sentimientos muy difícil de lograr de otra manera (...)"11. Las consideraciones de Rousseau sobre la civilidad y el refinamiento de las costumbres se conocen desde el Discurso sobre las ciencias y las artes. En la Carta, sin embargo, le resta pertinencia a esta manera de abordar el problema del teatro. Respecto del buen gusto, entendido como la expresión de la civilidad mundana a la cual alude D’Alembert, se pregunta: “¿Qué es en el fondo ese gusto tan alabado? El arte de ser un conocedor en pequeñas cosas"12.

Rousseau hace a un lado el argumento de D'Alembert y vuelve a plantear el problema de la utilidad del teatro en los términos que oponen desde el siglo XVII defensores y detractores del teatro: el de su utilidad moral. En la Carta cuestiona los argumentos de aquellos que sostienen que el teatro permite preservar las buenas costumbres y promover la virtud. Es decir, moralizar e instruir.

\section{La crítica a la utilidad moral del teatro.}

En el siglo XVIII los llamados philosophes son unánimes en considerar que el teatro tiene un valor moral y una función social: el teatro puede y debe instruir y moralizar. Diderot, proyectando las transformaciones anheladas para el teatro, escribe "He pensado, a veces, que se discutirían en el teatro los puntos más importantes de la moral, y esto sin alterar la marcha violenta y rápida de la acción dramática"13. En las Conversaciones sobre el hijo natural (1757), Diderot tratará justamente de las tensiones y desafíos que

\footnotetext{
${ }^{11}$ Art. Genève, en Diderot y D’Alembert (eds.), Encyclopédie ou Dictionnaire raisonné des sciences, des arts et des métiers, par une Société de Gens de Lettres, Paris, chez Briasson, David, Le Breton, Durand, tomo VII, 577b.

12 Lettre, p. 109.

${ }^{13}$ Citado por Belaval, Y., en L'esthétique sans paradoxe de Diderot, Gallimard, Paris, 1950, p. 19.
} 
implica para el teatro la transposición en el escenario del carácter moral de una acción. La representación debe ser "verdadera", porque de esa fidelidad al original depende su valor moral, y sin embargo debe mantener la tensión dramática y someterse a las condiciones del espacio y del tiempo escénico. Veremos que en la Carta Rousseau no va cuestionar la veracidad de la representación dramática sino los usos que de ésta hace el teatro mundano. Más allá de la promoción de la desigualdad ya señalada, el teatro mundano es culpable de pretender una "purgación" inexistente de las pasiones: purga pasiones que no tenemos y fomenta las existentes ${ }^{14}$. Al cuestionar la posibilidad de una purgación de las pasiones mediante la representación dramática, Rousseau inscribe su crítica al teatro en el marco de la contienda que opone defensores y detractores del teatro desde el siglo XVII en Francia.

\section{A. Rousseau entre defensores y detractores del teatro}

La contienda en torno al valor moral del teatro que opuso rigoristas y reformadores del teatro a lo largo de los siglos XVII y XVIII se funda en el reconocimiento del poder de la representación dramática ${ }^{15}$. Las representaciones "reales" tienen el poder de despertar las pasiones e influir en la conducta del espectador dentro y fuera del teatro. Donde rigoristas y reformadores se separan es en la consideración de los posibles usos de este poder. Analizaremos la posición de los rigoristas sobre la mimesis poética a través del Traité de la comedie et des spectacles (1667) de Armand de Bourbon Conti, quien retoma los argumentos de Pierre Nicole en el Traité de la Comédie (1666). Nos detendremos luego en la defensa que el abbé Du Bos

${ }^{14}$ Lettre, p. 20.

${ }^{15}$ Esta contienda que se conoce en Francia como la Querelle du théatre surge en los años 1630 a raíz de la iniciativa de Richelieu de promover, a través de la Academia de Francia, las condiciones de un reforma moral del teatro. La iniciativa dará lugar a lo que se llamó el "clasicismo" cuyos principios estéticos están sintetizados en L'art poétique de Boileau. La reforma del teatro despierta una virulenta oposición en la Iglesia de tradición agustiniana cuyos más ilustres representantes se encuentran en Port-Royal. Cfr. Bray, R., Formation de la doctrine classique, Nizet, 1927. Para un análisis más pormenorizado de esta contienda en el siglo XVIII, cfr. Moffat, M., Rousseau et la querelle du théatre au XVIII siècle, Saltkine, Ginebra, 1970. 
hace de la moralidad del teatro en Reflexions critiques sur la poésie et la peinture (1719) para poder situar la crítica de Rousseau.

En el Tratado sobre la comedia y los espectáculos ${ }^{16}$, Conti advierte sobre las consecuencias perniciosas de "esas expresiones acompañadas de una representación real"17. El poder de la representación "corrompe la imaginación" 18 afectando luego el entendimiento y las costumbres. La crítica del jansenista es interesante pues, a la vez que denuncia el poder de la representación teatral sobre la imaginación, le reconoce la posibilidad de instruir en virtud de ese mismo poder. La representación tiene más influencia sobre el pueblo que la palabra ${ }^{19}$. Es en virtud de este poder que los antiguos pretendían instruir mediante el teatro. Conti, como Nicole, no niega tal posibilidad al teatro, pero rechaza que ése sea el objetivo del teatro moderno. Con ironía, Conti sostiene que sólo en los libros de poética dramática la instrucción es el fin de la comedia, término con el cual designa todo los géneros teatrales ${ }^{20}$. Y esto por dos razones: el tema que domina la escena moderna es el amor, y la única pasión que subyace es el amor propio. El autor busca agradar, y el espectador ver representadas pasiones semejantes a las suyas. A través del teatro "nuestra propia persona reflejada desde el escenario se transforma en nuestro modelo" 21 .

El poder de la mimesis poética es usado por el teatro moderno para "conmover" las pasiones. Para nuestros autores, una vez que las pasiones han sido excitadas, ni el autor ni el espectador tienen poder sobre ellas. La representación teatral no puede purgar las pasiones. No se resiste a la voluptuosidad de la representación mediante la voluptuosidad de la escena amorosa. En este sentido, también Pierre Nicole combate la comedia porque, al representar el amor y buscar agradar, conmueve las pasiones en vez de combatirlas. La vida del verdadero cristiano sólo puede alcanzarse

${ }^{16}$ Conti A., Traité de la comédie et des spectacles selon la tradition de l'église, editor Luis Billaine, Paris, 1667. Edición electrónica de la Biblioteca Nacional de Francia: http://gallica.bnf.fr/

${ }^{17}$ Idem, p. 25.

${ }^{18}$ Idem, p. 25.

${ }^{19}$ Idem, pp. 26-28.

${ }^{20}$ Idem, p. 31.

${ }^{21}$ Idem, p. 32. 
reprimiendo las pasiones. El lugar de la instrucción para el cristiano es la iglesia y no el teatro. Es en la iglesia donde la palabra adquiere todo el poder que le confiere la representación dramática. Es en la iglesia que la representación dramática vuelve a instruir y moralizar...

Nicole, al igual que Conti, se aleja aquí de la concepción platónica de la mimesis poética. La imitación no es mala por reproducir apariencias, y inducir un falso saber. Es el uso que le da el teatro moderno lo que es condenado por él. No es posible, según el jansenista, usar todo el poder de la representación para interesar al espectador en el amor y luego pretender purgar las pasiones. Si bien no es posible purgar las pasiones una vez que la representación dramática las ha excitado, sí es posible concebir otro uso de la representación. Si el teatro termina siendo definitivamente condenado por Nicole no es, en consecuencia, por engañoso sino por ser ineludible en él el placer, "la voluptuosidad" de la representación. Sólo en la iglesia es posible inhibir el placer y desplegar todo el poder de la representación dramática.

En la Carta Rousseau no hace mención explícita a ninguno de los autores analizados. Son sin embargo sorprendentes los puntos de encuentro entre ambas críticas. Aunque no existe bajo la pluma del ginebrino una condena de la voluptuosidad per se, en ambos caso se hace hincapié en el monopolio que el amor tiene sobre la escena moderna en contraposición al teatro antiguo. Ambas críticas separan el potencial de la mimesis poética de la crítica a la catarsis. No conceden que la representación dramática pueda purgar las pasiones cuando estuvo orientada a excitarlas. Tanto los rigoristas como Rousseau se oponen en este punto a los defensores de la utilidad moral del teatro.

Así, en la Carta, Rousseau desplaza la relación establecida por D'Alembert entre el cultivo del buen gusto y el teatro para poder argumentar sobre el carácter amoral (cuando no inmoral) del teatro. El gusto, lo que la sociedad mundana llama "fineza de tacto", "refinamiento" es inseparable de las costumbres: del ethos, des moeurs, de la sociedad. Si el teatro puede formar el gusto es porque complace, si complace es porque reproduce y refuerza el ethos existente. El gusto y las costumbres son inseparables. No es posible reunir París y Ginebra sin transformar las costumbres, y, finalmente, la constitución de la comunidad política. La conclusión de Rousseau es lapidaria, el teatro lejos de corregir las 
costumbres refuerza el ethos nacional: "En ese sentido pareciera que limitándose a cargar y no a cambiar las costumbres establecidas, la comedia sería beneficiosa para los buenos, y dañina para los malos"22. Pero enseguida advierte, "faltaría todavía saber si las pasiones demasiado irritadas no degeneran en vicio". Contrapunto de la interpretación barroca de la catarsis: la exasperación de las pasiones tiene como efecto su aquietamiento ${ }^{23}$. Rousseau va a dirigir sus dardos contra la "poética del teatro" que pretende purgar las pasiones excitándolas. El texto remite explícitamente al abbé Du Bos y a Crébillon. Estas referencias le permiten ampliar la crítica de los rigoristas. La crítica de Rousseau está dirigida por un lado a la supuesta conversión de las pasiones que podría operar la representación dramática bien orientada. Es la tesis del abbé Du Bos. Y por otro, su crítica cuestiona el carácter ético de la piedad como efecto y afecto de la representación dramática. Es la tesis de Crébillon ${ }^{24}$.

En Reflexions critiques sur la peinture et la poésie ${ }^{25}$, el abbé Du Bos defiende el valor moral del teatro. Para Du Bos, como para Nicole, es posible hacer un buen uso de la mimesis poética, pero en contraposición a lo que sostiene el jansenista, este buen uso residiría en la posibilidad de "dirigir" las pasiones a través de la representación dramática, dado que el teatro es un arte capaz de representar tanto las acciones que inspiran a los hombres pensamientos virtuosos como aquellas que fomentan los vicios. Los efectos de la mimesis poética dependen de lo que se representa. La representación dramática es un "artificio" que si bien sólo produce una imitación de la verdad, ésta no es falsa ni engañosa. El placer de la representación no reside, insiste Du Bos, en la ilusión de confundirse con la verdad. Y, contestándole a Platón, agrega: muchas veces la imitación puede ser mejor que el original. Usada a favor de la virtud, la representación dramática es un socorro para la virtud. "La pintura de las acciones virtuosas calienta nuestra alma (...) el hábito de esas

${ }^{22}$ Lettre, p. 19.

${ }^{23}$ Gheeraert, T., "La catarsis impensable. La passion dans la théorie de la tragédic et sa mise en cause par les moralistes augustiniens", Etudes Episteme, №1, 2002, p. 118. ${ }^{24}$ Prosper Jolyot de Crébillon (1674-1762), autor entre otras tragedias de Atrée et Thyeste. Ia referencia a la catarsis que encontramos en La Carta proviene del prefacio a esta obra.

${ }_{25} \mathrm{Du}$ Bos, J.-B., Reflexions critiques sur la peinture et la poésie, 1719, edición electrónica de la Bibliothèque nationale de Francc: http://visualiseur.bnf.fr/ 
pasiones nos hace capaz de esfuerzos de virtud y de valentía que la razón sola no podría hacernos intentar" 26 . Las consecuencias de la imitación dependen, en última instancia, de los fines y del talento del poeta: "El buen poeta es aquel que sabe hacer amar cada vez más la sabiduría y la virtud" 27 .

Hasta aquí nuestros rigoristas podrían haber estado de acuerdo con el abbé, si tan sólo el teatro moderno se ocupara de reproducir acciones virtuosas y no meras pasiones amorosas. Para Du Bos, sin embargo, incluso cuando se representan los excesos de las pasiones, el teatro es aleccionador. El poema no sólo puede "instruir" haciéndonos amar la sabiduría y la virtud, también lo hace poniéndonos frente a los efectos nefastos de las pasiones: "Basta con tener presentes los efectos de esas pasiones violentas para no querer estar nunca bajo su dominio"28. En el teatro también es posible un aprendizaje a partir de las consecuencias de las pasiones. La tragedia produce en nosotros sentimientos contrarios a aquellos que expresan sus personajes.

B. La crítica a la catarsis poética en la Carta a D'Alembert.

Rousseau pone en duda esta concepción de la poética teatral remitiendo a una simple descripción fenoménica del estado emocional de espectador al salir de un espectáculo:

La emoción, la conmoción y el enternecimiento que sentimos en nosotros mismos y que se prolonga después de la obra, anuncia una disposición cercana a sobreponernos y ordenar nuestras pasiones? (...) ¿Son acaso propicias, las impresiones vivaces y conmovedoras a las cuales nos acostumbramos, y que vuelven tan a menudo, para moderar nuestros sentimientos en caso de necesidad? ${ }^{29}$

Rousseau se hace eco aquí de las objeciones de los detractores del teatro de inspiración agustiniana. El poeta puede controlar los efectos de las

\footnotetext{
${ }^{26}$ Idem, sección 5 , p. 49.

27 Idem, sección 5 , p. 49.

${ }_{28}^{28}$ Idem, seccion 44, p. 335.

${ }^{29}$ Lettre, p. 19.
} 
pasiones sobre sus personajes pero no sobre el espectador. Las emociones y conmociones del espectador no pueden ser reorientadas desde el escenario. La representación afecta, y la afección es poco propicia para inducir un "cálculo" sobre las consecuencias de las pasiones.

Además, Rousseau cuestiona doblemente la posibilidad de purgar las pasiones que la representación excita. Por un lado, la excitación crea en el espectador una mayor disponibilidad para la emoción; es más sensible, por lo tanto más propenso a ser afectado dentro y fuera del teatro. Por otro lado, a la supuesta transformación de los afectos representados en sus opuestos, el ginebrino responde con la descripción del contagio de las pasiones por identificación. Para poder aterrorizarse con las consecuencias de las pasiones hay que haberlas compartido con el personaje antes. "¿Por qué, se pregunta Rousseau, la imagen de las penas que nacen con las pasiones borraría las de la conmoción de placer y alegría que también vemos nacer y que los autores se empeñan en embellecer para hacer que sus obras sean más agradables?" 30 .

Por la misma razón que el espectáculo no provoca afectos contrarios a los que expresan los personajes representados, tampoco puede promover sentimientos que no existan ya en el espectador. En tanto el objetivo y el medio del espectáculo es el placer, el teatro se acomoda al gusto existente. Frente a aquellos defensores del teatro que, como Du Bos, pretenden que el teatro "bien dirigido" incita a amar la virtud y odiar el vicio, Rousseau sostiene que el teatro no hace más que reproducir lo que la naturaleza y la razón hacen sin el arte. "El amor de la belleza es un sentimiento tan natural del corazón humano como el amor de sí; no nace de un arreglo de la escena, el autor no lo crea, lo encuentra, y de ese sentimiento que alaba nacen las dulces lágrimas que hace correr" 31 . El teatro opera por imitación de la naturaleza, identificación y contagio.

El teatro podría entonces escuchar la naturaleza e incitarnos a la virtud, pero como ya lo ha advertido Nicole, ése no es el fin del teatro moderno. El teatro moderno busca agradar y nada más. Rousseau agrega: la tragedia nos muestra situaciones fabulosas y héroes inalcanzables que poco

${ }^{30}$ Lettre, p. 20.

31 Lettre, p. 21. 
tienen que ver con la imitación de sentimientos con los cuales nos podríamos identificar. La comedia, aunque más cercana a nosotros, sólo se ocupa de hacernos reír a expensas de la virtud. El análisis pormenorizado del Misántropo está orientado a confirmar la orientación del teatro moderno. Todo el cuidado de Molière, "el más perfecto de los autores cómicos" 32 , está orientado a "hacer que la bondad y la simplicidad quede en ridículo, y de poner a la astucia y la mentira del lado de nuestro interés. Su gente honesta son sólo personas que hablan; los viciosos, gente de acción que un éxito brillante favorece casi siempre" 33 .

Pero qué pasa cuando la representación provoca en nosotros compasión por el personaje que sufre, sentimiento natural que surge precisamente, según la propia definición de Rousseau, de la repulsión de ver sufrir a un semejante. Podría pensarse que el teatro sirve para rescatar ese sentimiento que la sociedad tiende a ahogar. "Oigo decir, escribe Rousseau, que la tragedia lleva a la piedad a través del terror" 34 . La naturaleza no hace otra cosa, de alguna manera. Aquí la representación imita la naturaleza. El problema de Rousseau respecto de la piedad no es ni la veracidad de la representación ni la sinceridad del sentimiento, sino su valor moral. ¿Qué valor puede tener la piedad si no lleva a la acción? En este punto Rousseau retoma de la crítica de San Agustín: el espectador no es invitado a ayudar sino sólo a dolerse ${ }^{35}$. La representación dramática anula el efecto moral de la piedad inhibiendo la "reacción" ante la miseria del otro. Los efectos de la piedad no salen de los muros del teatro produciendo una virtud de ostentación:

Es así como la más ventajosa de las impresiones de las mejores tragedias consiste en reducir a afecciones pasajeras, estériles y sin efecto todos los deberes del hombre, a hacer que nos aplaudamos por nuestro coraje cuando alabamos el de los demás, de nuestra humanidad cuando nos

\footnotetext{
32 Lettre, p. 31.

${ }^{33}$ Lettre, p. 32.

${ }^{34}$ Lettre, p. 23. Expresión que emplea Crébillon en el prefacio de Atrée (1770).

${ }^{35}$ Cfr. San Agustin, Confesiones, Buenos Aires, Colihuc Clásica, 2007, Lib III, cap II, p. 47.
} 
compadecemos por males que hubićramos podido curar, de nuestra caridad cuando decimos al pobre, "que Dios lo asista"36.

Los efectos de la tragedia no son nefastos sólo porque irritan las pasiones y llevan al desgobierno del alma, como ya sostenía Platón, sino porque incluso alli donde provocan sentimiento morales anulan la acción que debería resultar de ellos. La representaron dramática, a la vez que inspira la piedad, la anula como motor de la acción. Allí donde la naturaleza creó un impulso para la moralidad, el teatro promueve una parodia de la virtud. El espectador se conmueve por las miserias de los héroes del escenario para luego no apiadarse de nadie fuera del teatro. Todo el éfecto de la piedad se consume en el recinto del teatro.

\section{Mimesis poética y crítica al teatro.}

Para Platón el desgobierno del alma que produce la mimesis poética está directamente relacionado con su alejamiento de la realidad. Es porque reproduce apariencias, alejadas en tres grados del ser, que la mimesis afecta la parte pasional del alma. Los efectos nefastos de la mimesis poética resultan de su alejamiento de la naturaleza ${ }^{37}$. Rousseau, como Platón, atribuye a la mimesis poética un efecto perturbador sobre las pasiones. Pero a diferencia de lo que ocurre en República $X$, este efecto no es la consecuencia de la distancia que la mimesis poética mantiene con la realidad o naturaleza. La lectura que hemos hecho hasta aquí de la Carta nos ha permitido constatar que los argumentos usados por Rousseau para cuestionar los efectos del teatro no aluden a la falta de veracidad o a la ilusión que provoca la representación dramática. Como ya hemos hecho notar, la capacidad de imitación del hombre hace a su perfectibilidad moral. En la Carta, cuando Rousseau cuestiona la pretensión moralizadora del teatro, opone imitación y conmiseración. Moral no es quien se conmueve pasivamente ante el dolor, sino quien imita las acciones virtuosas. Lo que

${ }^{36}$ Lettre, p. 24.

${ }^{37}$ Platón, República, libro X, 597d-598b. 
está en cuestión en la moralidad "es actuar consecuentemente con sus principios, e imitar a las personas que estimamos" 38 .

Sin embargo, no están ausentes de la Carta las alusiones a la imperfección de la imitación poética en términos muy próximos a los del libro X de la República:

Es un error decía el valiente Muralt esperar que se muestre [en el teatro] fielmente la verdadera relación de las cosas: pues en general el poeta sólo puede alterar esa relación para acomodarla al gusto del pueblo. Es así como nunca están a su medida, y sicmpre vemos en el teatro seres distintos a nuestros semejantes. (...). ¿No es acaso una imitación bien entendida, aquella que se propone por objeto lo que no es, y deja, entre la falta y el exceso, lo que es como una cosa inútil? Pero qué importa la verdad de la imitación si se logra la ilusión ${ }^{39}$.

¿Suponen estas líneas la adopción de la concepción platónica de la mimesis poética? La referencia a la intencionalidad del poeta y a una imitación ilusionista nos permite otra lectura. La ilusión como meta de la imitación nos ubica nuevamente en los términos de la querella que opone defensores y detractores del clasicismo francés.

\section{A. Verosimilitud e ilusión en la imitación poética.}

Según el texto citado, lo que es queda fuera del escenario. Las verdaderas relaciones no interesan al poeta que sólo busca una ilusión de verdad capaz de arrancar los aplausos del público. La referencia a la intención del poeta nos permite separar la apreciación de la mimesis poética de la valoración de sus usos. La mimesis poética no es condenada por ser una forma no verdadera de reproducción de la realidad. Lo que hace no verdadera a la imitación poética es la intención que busca alterar la verdadera relación entre las cosas para adaptarse al gusto del pueblo. Es el poeta que busca la ilusión y no la imitación poética que conduce a ella indefectiblemente.

${ }^{38}$ Lettre, p. 22.

39 Lettre, p. 25 . Cursivas nuestras. 
Para el clasicismo francés una obra está lograda cuando consigue ilusionar al espectador. La ilusión buscada es aquella que logra que la razón abdique de su dominio y el espectador se olvide que está en el teatro. De la ilusión resulta tanto el placer como el posible uso moral de la obra.

Sostengo entonces que el fundamento de la imitación en todo poema es que ésta debe ser tan perfecta que no aparezca ninguna diferencia entre la cosa imitada y aquella que se imita, pues su principal efecto consiste en proponer al espíritu los objetos como verdaderos para purgar las pasiones excesivas $^{40}$.

La imitación bien entendida para el clasicismo es aquella que transporta ilusoriamente al espectador fuera del teatro. El criterio de la verosimilitud que rige al teatro clásico está orientado a confundir al espectador, no a acercarlo de la verdad. Hacerle creer en la veracidad de la representación es hacer que olvide que se trata de una representación. La verosimilitud despoja al espectador de la resistencia de la razón y lo somete al tratamiento escénico de las pasiones. El espectáculo busca "tomar" al espectador. De la conmoción que provoca, se espera, como lo sostiene Chapelain, tanto el placer como la purgación de las pasiones excesivas.

Para Rousseau, sin embargo, la confusión entre ficción y realidad que promueve el teatro clásico no sólo no tiene el efecto moralizador esperado sino que se hace en desmedro de la realidad. En La Nueva Eloísa el amante se indigna de la parcialidad del teatro parisino: "Hay en esta ciudad quinientas o seiscientas mil almas de cuya presencia nunca es cuestión en el escenario" 41 .

${ }^{40}$ Chapelain J., Lettre sur les vingt-quatre beures, in Opuscules critiques, ed. A. Hunter, Paris, Droz, 1936, p. 115. Citado por Gheeraert en "La catharsis impensable. La passion dans le théâtre classique de la tragédie et sa mise en cause par les moralistes augustiniens", Etude Episteme, No 2, 2002. Jean Chapelain (1595-1674) fue miembro de la Académie française y encargado de redactar la lista de los autores merecedores de la pensión del rey.

${ }^{41}$ Rousseau, J.-J., La nouvelle Hélö̈se, segunda parte, carta 17, Paris, Gallimard, 1993. 
En la Carta, Rousseau deja entrever otro uso de la imitación poética al exhortar a los ginebrinos a convertirse en autores antes de instalar un teatro en la ciudad. La mimesis poética en el teatro para la república no busca ni la conmoción ni la ilusión, sino rememorar e incitar a defender la libertad. La imitación admitida no es imitación de cualquier cosa". Pues no es bueno que se nos muestre todo tipo de imitación, sino únicamente aquella de cosas honestas propias de hombres libres" 42 .

Cuando la intención cambia, la imitación también. Los personajes de este teatro ya no son héroes fabulosos sino hombres comunes: “¿Quienes serán los héroes de nuestras tragedias, los Berthelier, los Lévrery? ¡Ay! dignos ciudadanos, habéis sido héroes no hay duda, pero vuestra oscuridad os envilece, y vuestros nombres comunes deshonran vuestras grandes almas" 43 .

Las repúblicas modernas se componen de hombres poco espectaculares, demasiado "oscuros" para el teatro mundano. La propuesta de Rousseau invierte los criterios del teatro clásico, abandona el héroe por el hombre común y las ficciones por la historia.

\section{B. La veracidad de la imitación poética.}

¿Qué concepción de la mimesis supone este otro teatro? ¿Es posible seguir hablando de una concepción platónica de la mimesis poética en Rousseau?

La única referencia textual a Platón en la Carta es el fragmento del libro III de la República, donde Platón festeja y excluye de la ciudad "al hombre hábil capaz de imitarlo todo" pues el plan de educación de los guerreros requiere de un poeta "más austero, menos agradable pero más útil" 44 . No encontramos mención de la definición platónica de la mimesis poética.

42 Lettre, p. 109.

43 Lettre, p. 110. Berthelier y Lévrery eran considerados mártires de la república helvética.

${ }^{44}$ Platon, Repuiblica, III, 398a. 
La definición de la mimesis y el problema de la veracidad tal como se plantean en la República no le eran, sin embargo, ajenos a Rousseau. Sabemos que éste preparó la Carta estudiando la cuestión de la imitación teatral en Platón. Un pequeño texto titulado La imitación teatral contiene los rastros de estas lecturas ${ }^{45}$. "Este texto, advierte, no es más que una reseña de distintos lugares donde Platón habla de la imitación teatral (...) La ocasión de este trabajo fue La Carta a D'Alembert sobre los espectáculos, pero no habiendo podido cómodamente hacerlo entrar, lo aparté para ser usado en otro lugar o bien totalmente suprimido" 46 . La Imitación teatral es la reconstrucción en prosa de la casi totalidad del libro X de la República, con pequeños agregados provenientes del Gorgias y de las Leyes. Rousseau transcribe la crítica platónica del arte mimético: el poeta mimético imita sin conocer, imita la realidad de segundo grado, y estas imitaciones no se hacen según lo que las cosas son sino según cómo aparecen. Los poetas imitan aquello que halaga a la multitud, y finalmente este arte con sus hechizos contribuye al desgobierno del alma: irrita las pasiones y anega la razón. La imitación de los poetas es condenada por "estar alejada de la verdad" y porque al "adular" la parte sensible del alma, descuidando la parte racional, invierte el orden de nuestras facultades y nos hace subordinar lo mejor a lo peor ${ }^{47}$. En la Carta, el "desgobierno" del alma aparecerá como una consecuencia de la identificación y del contagio de las pasiones producto de un cierto uso de la imitación por el poeta. Si Rousseau "aparta" finalmente las notas de lectura sobre la imitación teatral de la Carta es, con cierta probabilidad, porque no adopta totalmente la posición de Platón en su crítica al teatro. Rousseau va a distinguir el problema ético del problema ontológico. El cuestionamiento moral al teatro no va implicar para el ginebrino la negación de la capacidad de la imitación poética de expresar la naturaleza de las cosas, pero a condición de no entender la mimesis poética como una copia de la naturaleza.

En el cuarto paseo de las Ensoñaciones, Rousseau señala que las ficciones no son "engaños" por su relación con la verdad sino por su relación con la justicia. "Mentir sin beneficio, ni perjuicio para sí ni para

${ }^{45}$ Rousseau, J.-J., De l'imitation théâtral, Paris, Gallimard, 1995.

46 Ibidem, p. 1195.

47 Idem, p. 1208. 
otros, no es mentir, es ficción" 48 . Las fabulas pueden vestir de manera sensible y agradables verdades útiles. El amor a la justicia, afirma, puede ser "fabulador" 49 . Ahora bien, si el amor a la justicia puede ser fabulador es porque el criterio que rige la verdad no es el de la copia.

Para Rousseau, a diferencia de Platón, la imitación de la naturaleza no "copia" la naturaleza. La imitación no puede ser copia, porque la naturaleza no es una forma única que el entendimiento pueda concebir. La naturaleza carece de la evidencia que la omnipresencia de la palabra parece conferirle. La naturaleza es, pero su esencia es tan inaccesible como su presencia en el hombre. El hombre accede a la naturaleza, y a su naturaleza, por sus producciones. Y a estas producciones llama Rousseau “imitación”. Pero imitación de un original ausente. La imitación que las abarca a todas es el lenguaje, imitación y nunca copia...

Una nota de La Imitación teatral nos permite percibir la distancia que toma Rousseau respecto de la concepción platónica de la mimesis poética. Glosando el texto de Platón en República X 598-599, Rousseau sostiene que "hay arbitrariedad incluso en la imitación" 50. La acotación parece reforzar la posición platónica. La nota aclaratoria al pie de página nos introduce a otra concepción de la imitación. Para aclarar lo que entiende por "arbitrariedad" escoge dos ejemplos: la armonía y la pintura. Tomaremos el de la armonía. Arbitrariedad quiere decir bajo su pluma "convención", y se contrapone a "copia". La armonía es concebida por Rameau, contra quien Rousseau escribe, como imitación de la naturaleza, en el sentido de copia fiel. La armonía place porque reproduce las relaciones naturales entre los sonidos, es decir, copia la naturaleza. La armonía, sostiene Rousseau en cambio, es convención y no copia. Lo que hace que sonidos armónicos nos sean agradables es la costumbre. Es el tiempo, añade, que ha hecho de la armonía un arte de imitación. El "incluso" de la cita anterior enfatiza la imposibilidad de una copia de la naturaleza. Incluso en la imitación de los sonidos y de las formas hay convención.

\footnotetext{
${ }^{48}$ Rousseau, J.-J., Les rêveries du promeneur solitaire, Gallimard, Paris, 1959, p. 1029. ${ }^{49}$ Idem, p. 1030.

${ }^{50}$ Rousseau, Imitation théâtrale, p. 1198.
} 
En El ensayo sobre el origen de las lenguas reencontramos la controversia con Rameau en torno a la imitación. Rousseau vuelve a sostener, contra Rameau, que si concebimos la imitación como una copia, la música no imita a la naturaleza. En abierta polémica con el ilustre músico, Rousseau argumenta que la belleza de los sonidos pertenece a la naturaleza ${ }^{51}$ : "Todos los hombres del universos sentirán placer al escuchar bellos sonidos" 52 . Pero los sonidos, en tanto copia de la naturaleza, no llegan a conmovernos, no nos dicen nada: "Hágase lo que se haga, el ruido no dice nada al espíritu, es necesario que los objetos hablen para que se hagan entender; es necesario que en toda imitación una especie de discurso 'supla' la voz de la naturaleza" 53 . La imitación es el artificio que "suple" la voz de la naturaleza. La comunicación con la naturaleza no es inmediata. La naturaleza es ruido, para que nos hable es necesaria la mediación del artificio.

\section{A modo de conclusión}

Nuestra breve reconstrucción de la oposición entre reformadores y rigoristas en torno a la moralidad del teatro nos ha permitido separar, en la crítica rousseauniana, el juicio sobre la catarsis de la posición sobre la mimesis poética.

Cómo los rigoristas, Rousseau rechaza la pretensión del clasicismo de instruir y moralizar. El teatro no instruye porque el único tema que en él se representa es la pasión amorosa, y no moraliza porque es vana su pretensión de purgar las pasiones que excita. Rousseau agudiza la crítica de los rigoristas al atacar los efectos de la piedad en tanto afecto producido por la tragedia. La representación puede efectivamente conducir a la piedad, pero, a la vez que la provoca, la anula. La piedad para Rousseau no es simple conmoción de la sensibilidad. Es un afecto moral en tanto induce una reacción ante el dolor de un semejante. La piedad en el teatro queda presa de la representación. La supuesta catarsis no logra ni suprimir ni aquietar los excesos que la representación induce, pero sí puede anular los efectos de la piedad. La conmoción se torna éticamente condenable cuando sustituye a la

51 Rousseau, Essai sur l'origine des langues, Paris, Flammarion, 1992, p. 108.

52 Ibidem.

${ }^{53}$ Idem, p. 110. 
acción virtuosa. El espectador se contenta con sentir en vez de actuar. Al tratamiento escénico de las pasiones el ginebrino opone la fiesta, donde todos son actores y nadie espectador.

La crítica de la moralidad del teatro no se funda, pues, en la condena de la mimesis poética. El teatro no es inmoral porque la mimesis poética sea engañosa. Rousseau deja incluso entrever la posibilidad de una apropiación republicana de la mimesis poética.

Para el ginebrino la mimesis es mediación necesaria entre la naturaleza y el hombre, el hombre y su propia naturaleza. Si la imitación degenera en sociedad es por el uso que de ella se hace, y no por estar alejada de la verdad. El valor de la imitación no se mide por su relación con la verdad sino por su relación con la justicia. La imitación no se define, como en Platón, por su cercanía o lejanía con la naturaleza porque no es concebida por Rousseau como copia sino como suplemento. Sin este suplemento no hay historia y de la naturaleza sólo nos llega el ruido...

Recibido: 03/2010; aprobado: 06/2010. 